\title{
Male Youths' Perceptions, Knowledge and Beliefs of Alcohol Misuse and HIV Prevention
}

\author{
Eugene Gabriel Machimana \\ University of Pretoria, Department for Education Innovation, SOUTH AFRICA
}

Phillip Nhlanhla

University of South Africa, Department of Sociology, SOUTH AFRICA

Received: 7 January 2020 • Accepted: 7 March 2020 • Published Online: 17 March 2020

\begin{abstract}
This study investigated alcohol misuse associated with risky sexual behavior, which poses a challenge in South Africa, where the rate of HIV transmission is high. Southern Africa faces the challenge of HIV risk behavior, which is linked to the misuse of alcohol. The use of the qualitative research methodology was appropriate, as the researchers were interested in gaining a deeper insight into and understanding of male youth's perceptions. The findings also indicate that alcohol has a negative impact on HIV prevention. Unprotected sex, which is connected to alcohol misuse, is one of the ways in which the HIV pandemic is perpetuated. We recommend that a policy should be developed and implemented, with regards to the integration school programs on HIV and alcohol use, in order to enable young people to prevent HIV infection. Raise ongoing awareness of alcohol abuse in communities, in order to reduce the rates of HIV transmission.
\end{abstract}

Keywords: AIDS, masculinity, misuse, risky behavior, unprotected sex.

\section{Introduction}

This paper presents a study that investigated alcohol misuse associated with risky sexual behaviour, which poses a challenge in South Africa, where the HIV transmission rate is high. Literature shows that Southern Africa is faced with the challenge of HIV risk behaviour that is linked to the misuse of alcohol (Kalichman, Simbayi, Kaufman, Cain \& Jooste, 2007; Majozi 2009). Kalichman, Simbayi, Kaufman and Jooste (2006) report that the percentage of males who engage in sexual intercourse after using alcohol is higher than that of females, which is $56 \%$ and $25 \%$ respectively. The higher percentage of male youths consuming alcohol in the sexual context necessitated the current study, because some of them have unprotected sex with unfamiliar partners. It is partly for this reason that this research was conducted at the Health and Welfare Organisation in Soshanguve, Gauteng province, where there are male youths who attend HIV prevention programmes. Kalichman et al. (2006) support this claim by highlighting the urgency of HIV prevention interventions in South Africa. HIV prevention intervention strategies should also address the influence of alcohol on the spread of HIV.

(C) Authors. Terms and conditions of Creative Commons Attribution 4.0 International (CC BY 4.0) apply. Correspondence: Dr Eugene Gabriel Machimana, University of Pretoria, Department for Education Innovation, Unit of Community Engagement, Private Bag x20, Hatfield, Pretoria, o028, SOUTH AFRICA. Email: eugenemachimana@gmail.com. 
E. G. Machimana \& P. Nhlanhla - Male Youths' Perceptions, Knowledge and Beliefs of Alcohol...

A study conducted by Parry, Rehm and Morojele (2010) confirm that there is conclusive evidence to link alcohol use with the spread of HIV. In South Africa, an individual who drinks alcohol consumes on average 20 litres of alcohol per year, which is the highest volume compared to other countries in the world. Kalichman et al. (2007) report that about $40 \%$ of South African males consume more alcohol, and indulge in HIV risk behaviour, compared to about $15 \%$ of their female counterparts. The age group that was targeted for the study is said to be at greater risk of contracting HIV, which is influenced by alcohol misuse, yet they are an appropriate age for HIV prevention programmes. Therefore, many of them can be reached by HIV prevention messages before they contract the virus.

- Alcohol has a negative impact on HIV prevention.

- There is a lack of knowledge among male youth regarding the risk factors that lead to HIV infection, including the abuse of substances such as alcohol.

- Many of these youths do not associate this with HIV/AIDS, and if they do not have knowledge, it becomes difficult for them to look after themselves and others.

- Male youths think of themselves as being invincible, as if they "may not" be infected with HIV. It is egocentrism that leads to personal myths, which cause some male youths to engage in risky sexual behaviour, such as having sex without using a condom.

- The information gathered during the face-to-face interviews could be used to improve the HIV prevention programme of the organisation.

- The main recommendations include the following: a policy should be developed and implemented; there should be formal, integrated school programmes on HIV, in order to enable young people with regard to HIV prevention.

- Moreover, gender dynamics and cultural issues should be addressed, as people have used them incorrectly to their sexual benefit, which has in turn resulted in the spread of HIV. In addition, raise ongoing awareness of alcohol abuse in communities, in order to reduce the rates of HIV transmission.

The misuse of alcohol poses a significant health risk to an individual, especially in the era of the AIDS pandemic. A study conducted by Weir, Pailman, Mahlalela, Coetzee, Meidany and Boerna (2003) in a Cape Town township found that $94 \%$ of the people who participated in the study reported that places which sell alcohol were the most common places where people met new casual sex partners. Furthermore, the above study indicates that only 60\% of these research participants had used a condom during their last sexual encounter. The $40 \%$ of people who did not use condoms during sex were at risk of contracting HIV if any of their partners were infected with the virus. Kalichman et al. (2007) report that males are more likely to drink than females, and then to have unprotected sex with different partners. Such behaviors put male youths at risk of contracting HIV, especially when they are under the influence of alcohol.

\section{Literature review}

\subsection{Initiation into alcohol consumption and subsequent misuse}

Recent trends show that youths living in cities start drinking as young as 13 years of age (Stueve \& O'Donnell, 2005). The age at which youths start drinking alcohol plays a role in terms of their immediate and long-term risk-taking behavior. Some youths who start drinking alcohol during adolescence tend to have alcohol misuse and dependency problems for the rest of their lives. The counter argument by Galanter (2006) suggests that it is debatable whether early initiation into alcohol will result in alcohol problems, or if it is an early sign of a potential problem. The potential problem of alcohol misuse may be complicated by factors such as genetic and family 
characteristics. This means that families with a history of alcohol misuse usually pass it on to their offspring.

Researchers have different standards of defining "risky drinking." Morejele, Kachieng'a, Mokoko, Nkoko, Parry, Nkowane, Moshia and Saxena (2006) suggest that when a male drinks more than five standard drinks per day during the weekend, this could be classified as harmful drinking. Females only need to drink at least three standard drinks per day for their behavior to be defined as risky. Stueve and O'Donnell (2005) warn that risky drinking increases the chance of exposure to HIV and other sexually transmitted infections (STIs), such as syphilis. Early alcohol misuse among youths may affect their judgment, school performance and expose them to risk-taking environments such as taverns. Stueve and O'Donnell (2005) further caution that early alcohol misuse exposes urban youths to risky behaviors that may endanger their health and wellbeing. Male youths who start drinking early in life usually report alcohol problems, multiple sex partners, unprotected sex, and being drunk during sexual intercourse. It is important to target male youths with HIV prevention programs before they start misusing alcohol or initiating sex with their partners (Stueve \& O’Donnell, 2005).

\subsection{Alcohol misuse, multiple sexual partners and HIV risk}

Research shows that as early as 1901, there was a link between alcohol misuse and the risk of contracting STIs such as syphilis (Cook \& Clark, 2005). Karim and Karim (2010) define STIs as infections caused by bacteria, fungi, protozoa and viruses that are passed on through sexual intercourse. Cook and Clark (2005) further state that recent studies affirm that youths who misuse alcohol are more likely to report cases of STIs. Drinking patterns play a role in risk-taking behavior that leads to the spread of STIs. People who occasionally consume wine at dinner are less at risk than youths who are often intoxicated at parties, and subsequently engage in sex with multiple partners (Trichopoulou, 2001; Machimana, 2012).

Alcohol misuse puts youths at risk of contracting HIV, because of its effect on behavior or its adverse effect on the immune system (Cook \& Clark, 2005). For example, Karim and Karim (2010) affirm that STIs may cause inflammation of the genitals and increase the susceptibility to HIV infection. Untreated STIs accelerate the rate of progression of HIV to AIDS in people living with HIV (Karim \& Karim 2010). Young people aged 15 to 24 years who report having unusual genital discharge and genital ulcers are more at risk of HIV infection (Pettifor, Rees, Kleinschmidt, Steffenson, MacPhail, Hlongwa-Madikizela, Vermaak \& Padian, 2005). The duration of the progression of HIV to AIDS is dependent on the effectiveness or strength of the immune system, among other things.

A study conducted by Simbayi, Mwaba, and Kalichman (2006) showed that $16.2 \%$ of people with multiple partners were significantly more likely to report alcohol consumption than the $8.3 \%$ of people with one partner, who did not consume alcohol. The study also found that people who frequently used alcohol were less likely to use condoms during sex. The findings of this study are supported by an international study, which indicates that people who drink heavily are more likely to engage in sexual intercourse with multiple partners (Rutledge, Siebert \& Wilke 2008). Juma and Klot (2011) claim that young men view multiple partners as a "strategic" and "recreational" way of ensuring the availability of women to satisfy their sexual needs. Young men tend to have multiple partners in order to protect themselves against disappointment, as they will have a choice as to which women they can have sex with. Heavy drinkers have been found to have more sexual partners than non-users of alcohol, and this poses the risk of transmitting HIV.

Research has shown that the misuse of alcohol not only influences HIV risk behaviour, but can also have detrimental effects on individuals who are already living with HIV. Van Dyk (2001) asserts that the use of alcohol is linked to the suppression of the immune system, lowering 
of the CD4 cell count, as well as increased chances of contracting other STIs. Heavy drinking among people living with HIV affects their immune system negatively, thereby accelerating the rate of progression to the AIDS stage, which is the final phase of the disease (Majozi, 2010).

\subsection{Masculinity in the context of HIV risk}

The concept of masculinity originated in the mid-1980s and has established a link in terms of research in men's studies (Connell \& Messerschmidt, 2005). Masculinities are created both at the social and psychological levels, and can be understood as patterns of practice that perpetuate the dominance of men over women. The practice of dominance by men over women is structurally supported, and in some African societies, women are subjected to violence daily (Ratele, 2008). In South Africa, economic and social inequality is seen as one of the factors that makes African women vulnerable to structural dominance by men (Albertyn, 2003; Machimana, 2012). Oppong, Oppong and Odotei (2006) point out that women were most severely impacted by the decline of the economy in Ghana. Linked to the concept of gender inequality in African societies, women find themselves to be most at risk for HIV infection. It is therefore critical to explore the role of the masculinity factor in HIV risk among male youths. Gender inequity that violates the sexual rights of women poses HIV risks for both males and females (Machimana, 2018). Connell and Messerschmidt (2005) indicate that masculinity is used to study men's health practices, such as risky sexual behaviour.

The belief that alcohol stimulates sexual desire contributes to its consumption before sexual intercourse. Nolen-Hoeksema (2008) reasons that alcohol may impair sexual judgment and expose the user to the risk of HIV infection. Forut (2010: 4) suggests that "masculinity" is linked to having multiple partners, drinking alcohol and engaging in promiscuous behaviour. Harrison, O’Sullivan, Hoffman, Dolzal and Morrell (2006) argue that men tend to have their first sexual intercourse at a younger age and have more sexual partners than women. This is a negative expression of masculinity, and is sometimes associated with sexual coercion, which makes women vulnerable to HIV infection. In addition, rape cases are reported in situations where men want to impose their masculinity on women (Ratele, 2008). For instance, a woman was gang-raped at a bus terminus in Swaziland because she wore a miniskirt. Ratele (2008) reports a similar incidence of gender-based sexual violence at a Johannesburg taxi rank, where men inserted their fingers into a woman's vagina because she wore a miniskirt.

It is essential to engage men in the process of combating gender-based violence against women. The Development of Community Knowledge and Direct Access (DOCKDA) is one of the organisations that have pioneered projects that engage men in addressing gender-based violence in the Northern Cape Province, in South Africa. DOCKDA (2011) aims at addressing the spread of HIV by including men in gender-based violence projects. Men are actively involved as facilitators in some of the workshops, in order to curb gender-based violence against women. The engagement of men will be of benefit to both genders in South Africa, where different forms of the negative expression of masculinity are displayed against women. Ratele (2008: 519) adds that more men are challenging "masculinity", and this a positive step towards addressing HIV risk.

\section{Methodology}

\subsection{Qualitative research methodology}

The use of the qualitative methodology was appropriate to this study, as the researchers were interested in obtaining an in-depth insight into and understanding of the perceptions of the association between alcohol misuse and the risk of HIV infection among male youths (Babbie \& Mouton, 2001). Glesne (2006) indicates that this design allows the researchers 
to contextualise and interpret the complexity of the experiences, feelings and thoughts from the male youths' perspective, rather than from the researchers' perspective. Purposive sampling was used in this study. The sample comprises fourteen male youths $(n=14)$ between the ages of 16 and 20 years.

\subsection{Data analysis: Inductive thematic analysis}

The first step in thematic analysis involves reading and rereading the transcriptions in order to obtain an overall idea of the research participants' responses. The process involves identifying common patterns in the data, which were interpreted according to the Social Learning theory and Health Belief Model (Neuman, 1997). The emerging themes were grouped and named accordingly. From the emerging themes, meanings were formulated and clustered into subthemes. Flick, Von Kardorff and Steinke (2004) state that this helps to classify the different patterns in data according to analytical themes. Braun and Clarke (2006) affirm that the last step involves integrating all emerging themes into an in-depth description of the male youths' perceptions.

\subsection{Theoretical framework: Social learning theory}

According to Albert Bandura (1986), behaviour is a result of the interaction between cognition, behaviour, environment and physiology (Airhihenbuwa \& Obregon, 2000). Bandura's theory is relevant to this study, because alcohol affects both cognition and behaviour. Adolescents are vulnerable to impaired judgment under the influence of alcohol, with the risk of engaging in unprotected sex. Brannon and Feist (2004) argue that Social Learning theory explains alcohol consumption as a socially learned behaviour through modelling. Schultz and Schultz (2005) assert that Bandura developed the Social Learning theory for the purpose of modifying learned behaviours that are regarded as unwanted in society. In this study, risky sexual behaviour associated with alcohol misuse may be addressed through the Social Learning theory.

\subsection{Ethical considerations}

The researchers negotiated access to interview male youths who are supported and trained by the health and welfare organisation in Soshanguve. Nong (2011), the Chief Executive Officer (CEO) of the health and welfare organisation, who has the authority to control access, represented the management of the institution. Access to the research participants was granted, without imposing any demands on the research process. Babbie and Mouton (2001) indicate that it is important to provide details and explain the reason for conducting the research, so that the research participants can make an informed decision about their participation. Neuman (1997) agrees that ethical researchers should disclose the full details of the purpose of the research project. In this study, the researchers did not withhold or provide incorrect information, and the research participants agreed to participate based on the correct understanding of the requirements of the research project.

\section{Results}

4.1 Male youths' perceptions, knowledge and beliefs of alcohol misuse and HIV prevention

The findings of this research are discussed under this broad theme, namely the male youths' perceptions, knowledge and beliefs of alcohol misuse and HIV prevention. The theme is 
E. G. Machimana \& P. Nhlanhla - Male Youths' Perceptions, Knowledge and Beliefs of Alcohol...

supported by three sub-themes that emerged during the face-to-face interviews, as discussed below.

\subsubsection{Knowledge about the role of alcohol misuse on HIV prevention}

The researchers asked the research participants the following question: "How can alcohol misuse facilitate the risk of contracting HIV?" The following quotes reflect the sentiments of the participants regarding the role of alcohol misuse in hindering HIV prevention:

"At the same time, male youths go to their girlfriends' homes and sleep with them. And in a drunk situation, whereby they do not even use condoms. When they do not use condoms there is more possibility of getting infected with HIV" (Participant 1).

to HIV:

Participant 2 supports the claim that lack of knowledge makes male youths vulnerable

"HIV is an infection that affects our society. Mainly the youths because where we are in fact where we are you cannot say there is no knowledge. We do not care about the information that we have" (Participant 3).

The following response highlight the risk of meeting a sexual partner at a tavern, whose HIV status is not known:

"HIV infection, you see youths, us, we like alcohol and go to shebeens and drink alcohol. You meet someone like a girl in a shebeen, you talk to her. You buy her alcohol to drink and after she is drunk you take her. You tell her, let's go to see my place and you go there. They have sex without using a condom and that is how he contracts AIDS." (Participant 5).

\subsubsection{Alcohol misuse among male youths}

Most of the research participants believe that alcohol misuse can increase the risk of contracting HIV. Only one research participant made it clear that alcohol in itself does not pose an HIV risk, but rather the risky behavior of the male youths when they are intoxicated. The following is what the research participants had to say in response to the question: "How can alcohol misuse facilitate the risk of contracting HIV?":

"When young people are abused at home, they think that the easiest way to solve their problems is to have sex or drink alcohol; after drinking alcohol and having sex." (Participant 1).

"Alcohol can facilitate the risk of HIV and AIDS by drinking it a lot. Some males when they drink alcohol, they no longer know who they are. So we differ, so somebody who drinks too much always is no longer sober, can contract HIV because he does not know what he is doing after drinking alcohol." (Participant 3).

Participant 4 explains how some male youths expose themselves to HIV when they are under the influence of alcohol:

"As I said you get a girl at the tavern, you take her and you forget to use a condom. And that girl has AIDS, you forgot to use a condom and you have sex."

Participant 11 was the only one who mentioned that alcohol on its own cannot expose male youths to HIV infection. He understands the distinction between alcohol misuse and the risk of contracting HIV because of risky sexual behaviour:

"They can get HIV by having sex. But those who drink alcohol only cannot get HIV." 


\subsubsection{The use of condoms during sexual intercourse}

There were two participants who reported that failure to use condoms is attributed to females who complain that it is painful. Others fail to use condoms because they have sex under the influence of alcohol. Participant 1 was the only one who was sceptical about the use of condoms, because they may burst during sex, which poses the risk of contracting HIV. He recommends that people should be faithful to one partner, in order to prevent the spread of HIV. The following extracts highlight male youths' perceptions of condom use:

"We do not use condoms, and some girls do not want condoms. Some girls say a condom is painful. Some boys want condoms more than the girls." (Participant 5).

"People say they cannot eat a banana with its skin." (Participant 12).

Despite the reluctance of some male youths to use condoms, participant 6 indicates that "It is good to use condoms because it protects against AIDS". Proper and consistent use of condoms is one of the means of preventing HIV, although there is evidence that male youths neglect to use them:

"It is a very good thing because we need condoms when it comes to some situations. Because now more people are infected with HIV and AIDS. More people will get it from having sex without protection." (Participant 14).

Some male youths coerce their sexual partners into having unprotected sex. Participant 14 made the following comment when responding to the question on the use of condoms:

"But others they just avoid to use a condom, because for example maybe a boy can tell a girl that we must have sex and that girl does not want to have sex. She will say, I am not ready to have sex with someone. That boy will say, if you do not have sex with me without a condom, it shows that you do not love me."

\section{Discussion}

5.1 Male youths' perceptions, knowledge and beliefs of alcohol misuse and HIV prevention

The discussion follows a similar structure to the findings above.

\subsection{Knowledge about the role of alcohol misuse on HIV prevention}

The research participants indicated that alcohol has a negative impact on HIV prevention. They highlighted that some male youths indulge in unprotected sex when they are intoxicated because of alcohol. Unprotected sex, which is sexual intercourse without using a condom, is a hindrance to HIV prevention. Having unprotected sex, which is connected to alcohol misuse, is one of the ways in which the spread of the HIV pandemic in South Africa is perpetuated. The following quotation illustrates this point:

"Because you drink alcohol, overdose, and then you get some girls outside. Then that girls go with you at home, sleep with you and you do not condomise, so you can get HIV." (Participant 7).

Participant's 7 comment is consistent with the findings of other studies that were reviewed. For example, Kalichman et al. (2007) state that unprotected sex with different partners is common among people who misuse alcohol. Alcohol misuse is reported to encourage male youths to have multiple sexual partners. The concept of multiple sexual partners could either refer to one male youth having more than one female sexual partner, or vice versa. An example of this is given in the following statement: 
E. G. Machimana \& P. Nhlanhla - Male Youths' Perceptions, Knowledge and Beliefs of Alcohol...

"Male youths drink and after drinking is where they start to have sex with her because of alcohol. She cannot see who is sleeping with her because she is drunk." (Participant 8).

Morejele et al. (2006) and Mangerud, Bjerk, Holmen, Lydersen and Indredavik (2014) indicate that alcohol misuse is associated with HIV infection, which has consistently been linked to the risky behaviour of having multiple sexual partners. In some cases, multiple sexual partners is related to power play, where male youths use their masculinity to dominate women. Jabu, a male student, reports how he trapped a female student into having sex against her will:

"I invited her into my room. Once she was in my room, I started to make my move. I touched her hand, and when she did not pull away, I started playing with her fingers. Next thing we were kissing and we had sex.” (Juma \& Klot, 2011).

In this study, the male youths know that the risk of HIV is associated with alcohol misuse. They are aware of safe sex, although the research findings still report cases of unprotected sex among male youths.

\subsection{Alcohol misuse among male youths}

Most of the research participants are aware of the dangers of the misuse of alcohol among male youths. The research participants warn that alcohol misuse may expose male youths to HIV and interfere with their academic development. Participant 1 was the only research participant who made a clear distinction between alcohol misuse and risky behaviour. His point highlights that alcohol itself does not transmit HIV, but rather the risky behaviour associated with the misuse of alcohol.

Participant 11 commented as follows:

"They can get HIV by having sex. But those who drink alcohol only cannot get HIV".

The following extract highlights the feelings of the male youth about alcohol misuse:

"As youths we should abstain from sex and alcohol, use condoms, more, especially when we talk about alcohol. Alcohol is not good for youths because you cannot control yourself after drinking." (Participant 10).

The research participants in the study are living in an urban township, namely Soshanguve. As such, people living in urban townships and informal settlements are more vulnerable to HIV in South Africa. Kalichman, Simbayi, Vermaak, Jooste, and Cain (2008) state that HIV in South Africa is exacerbated by substance misuse, with alcohol being the most misused substance. In this regard, Kalichman et al. (2006) report that alcohol is the most commonly misused substance and 39\% of male youths aged between 10 and 21 years drink alcohol. The studies mentioned above support the findings of this current study in Soshanguve, Gauteng province.

Moreover, alcohol misuse and unsafe sexual behaviour are associated with specific populations and specific risk situations. Pettifor et al. (2005) assert that alcohol is associated with HIV risky behaviour in drug users. Some people who misuse alcohol are more prone to having a history of injecting themselves with drugs (Kalichman et al., 2006; Machimana, 2012; Mangerud et al., 2014).

Participant 5's comments support the literature:

"You see when male youths, use injections, after I have used the injection, I pass it on to someone through blood."

Contaminated blood exchange is a known means of HIV transmission. 


\subsection{The use of condoms during sexual intercourse}

The majority of the research participants emphasised that male youths do not use condoms. Some of the excuses given for not using condoms are related to the youths' mythical analogies. For example, "people say they cannot eat a banana with its skin. They are only fooling themselves" (Participant 12). Few individuals have made their stand, where this is contrary to the myths about condom use.

Participant 11 said:

"I feel good about it, so that I should not be sick. So that I should not be infected with $H I V$ ".

Participant 11's opinion regarding condoms is in agreement with the literature on the value of condoms. The Health Belief Model indicates that the perceived severity of an illness encourages people to take proactive steps to prevent diseases (Feist, 2004).

According to Lancet (2007), condoms serve as a protection (80 to 90\%) against HIV if they are used consistently and properly. The concern that was raised by some male youths about condoms bursting shows that they do not use them correctly. Lancet (2007) expounds on condom use and links its added value to male circumcision, meaning that male circumcision contributes significantly in HIV-prevention if it is complemented with proper and consistent condom use. The question that arises about male circumcision is whether it has or will have a negative impact on the use of condoms among male youths. This issue did not surface in this current study as it was not the main focus, but this is worth exploring in future research.

Some male youths find themselves in a dilemma, especially when a female rejects the use of a condom during sexual intercourse.

"Some girls say a condom is painful. Some say I do not want a condom, a condom damage me, you see" (Participant 5).

Karim and Karim (2010) report on young women of 15 to 24 years, who complain that male condoms make sex less pleasurable. The negative attitude towards condoms will discourage male youths from using condoms during sexual intercourse.

misuse:

Participant 13 warns that some male youths' failure to use condoms is due to alcohol

"They do not use condoms. Because when they get drunk, they want to enjoy what they are doing. If you are drunk you cannot even think about a condom".

As reported in the research findings, male youths sometimes use alcohol to "buy sex". Norris, Kitali, and Worby (2009) confirm that in some cases, sex is used in exchange for alcohol, food or gifts, and it is referred to as transactional sex. Transactional sex is commonly reported with reference to women, but transactional sex also occurs between young men over alcohol (Lane, Raymond, Dladla, Rasethe, Struthers, McFarland, \& McIntyre, 2009). In this study, only one research participant reported being involved in a same-sex relationship, but was not necessarily involved in transactional sex.

In summary, many adolescents do not use condoms, notwithstanding its value in HIV prevention. When male youths avoid using condoms, they increase the probability of contracting STIs, including HIV.

\section{Conclusion}

This paper reviewed a study conducted to investigate male youths' perceptions, knowledge and beliefs of alcohol misuse and HIV prevention. The data was collected by means of 
face-to-face interviews with the participants. The study found that there is a lack of knowledge among male youth regarding the risk factors that lead to HIV infection, including the abuse of substances such as alcohol. Many of these youths do not associate this with HIV/AIDS, and if they do not have knowledge, it becomes difficult for them to look after themselves and others. It is remarkable that some of the views of the male youths coincide with the studies conducted by other researchers. The study found that male youths think of themselves as being invincible, as if they "may not" be infected with HIV. It is egocentrism that leads to personal myths, which cause some male youths to engage in risky sexual behaviour, such as having sex without using a condom. Male youths need more than HIV information to cope with social challenges, which are complicated by the dynamics of alcohol misuse and the HIV pandemic.

The information gathered during the face-to-face interviews could be used to improve the HIV prevention programme of the organisation. The main recommendations include the following: a policy should be developed and implemented; there should be formal, integrated school programmes on HIV, in order to enable young people with regard to HIV prevention. Moreover, gender dynamics and cultural issues should be addressed, as people have used them incorrectly to their sexual benefit, which has in turn resulted in the spread of HIV. In addition, raise ongoing awareness of alcohol abuse in communities, in order to reduce the rates of HIV transmission.

\section{Acknowledgements}

Special words of gratitude go to the Health and Welfare Organisation in Soshanguve, South Africa, and the male youth who participated in this study. Many thanks for their participation in this study by sharing their invaluable knowledge.

This research did not receive any specific grant from funding agencies in the public commercial, or not-for-profit sectors.

The authors declare no competing interests.

\section{References}

Airhinenbuwa, C. O., \& Obregon, R. (2000). A critical assessment of theories/models used in health communication for HIV/AIDS. Journal of Health Communication, 5, 5-15.

Albertyn, C. (2003). Contesting democracy: HIV/AIDS and the achievement of gender equality in South Africa. Feminist Studies, 29(3), 594-615.

Babbie, E., \& Mouton, J. (2001). The practice of social research. South African edition. South Africa: Oxford University Press.

Brannon, L., \& Feist, J. (2004). Health psychology: An introduction to behaviour and health. $4^{\text {th }}$ edition. Australia: Thomson Wadsworth.

Braun, V., \& Clarke, V. (2006). Using thematic analysis in psychology. Qualitative Research in Psychology, 3, 77-101.

Connell, R. W., \& Messerschmidt, J. W. (2005). Hegemonic masculinity rethinking the concept. Gender \& Society, 19, 829-859.

Cook, R. L., \& Clark, D. (2005). Is there an association between alcohol consumption and sexually transmitted diseases? A systematic review. American Sexually Transmitted Diseases Association, 32(3), 156-164. 
DOCKDA (2011). The development of community knowledge and direct access. Skills programme report. 1-4.

Flick, U., Von Kardoff, E., \& Steinke, I. (Eds.). (2004). A companion to qualitative research. London: Sage.

FORUT (2010). Alcohol and HIV/AIDS- possible connections. Retrieved 3 May 2019, from www.addresources.org/alcohol-and-hivaids-posible-connections/.

Galanter, M. (Ed.). (2006). Alcohol problems in adolescents and young adults: Neurobiology, prevention and treatment. New York: Springer.

Glesne, C. (2006). Becoming qualitative researchers: An introduction. $3^{\text {rd }}$ edition. Boston: Pearson Education.

Juma, M., \& Klot, J. (Eds.). (2011). HIV/AIDS, gender, human security and violence in South Africa. Pretoria: Africa Institute of South Africa.

Kalichman, S. C., Simbayi, L. C., Kaufman, M., \& Jooste, S. (2006). Sensation seeking, alcohol use, and sexual behaviours among sexually transmitted infection clinic patients in Cape Town, South Africa. Psychology of Addictive Behaviours, 20(3), 298-303.

Kalichman, S. C., Simbayi, L. C., Kaufman, M., Cain, D., \& Jooste, S. (2007). Alcohol use and sexual risks for HIV/AIDS in Sub-Saharan Africa: Systematic review of empirical findings. Society of Prevention Research, 8, 141-149.

Kalichman, S.C., Simbayi, L.C., Vermaak, R., Jooste, S., \& Cain, D. (2008). HIV/AIDS risks among men and women who drink at informal alcohol serving establishments (Shebeens) in Cape Town, South Africa. Society for Prevention Research, 55-62.

Karim, Q. A., \& Karim, S. S. A. (Eds.). (2010). HIV/AIDS in South Africa. $2^{\text {nd }}$ edition. Cape Town: Cambridge University Press.

Lane, T., Raymond, H. F., Dladla, S., Rasethe, J., Struthers, H., McFarland, W., \& McIntyre, J. (2009). High HIV prevalence among men who have sex with men in Soweto, South Africa: Results from the men's study. Springer, 626-634.

Machimana, E. G. (2012). Perceptions of the association between alcohol misuse and the risk of HIVinfection among male youths in Soshanguve, Gauteng province, Masters dissertation, University of South Africa, Pretoria. Retrieved 12 April 2018, from http://uir.unisa.ac.za/bitstream/handle/10500/9129/Dissertation machimana eg.pdf?sequ ence $=1 /$.

Machimana, E. G., Sefotho, M. M. \& Ebersöhn, L. (2018). What makes or breaks higher education community engagement in the South African rural school context - A multiple-partner perspective. Education, Citizenship and Social Justice, 13(2), 177-196 https://doi.org/10.1177/1746197917731353

Majozi, P. N. N. (2009). Investigating anxiety and social support in adults diagnosed with HIV or AIDS in a public health facility in the Western Cape Province. Masters dissertation, University of the Western Cape, Cape Town. Retrieved 15 June 2018, from http://etd.uwc.ac.za/xmlui/bitstream/handle/11394/3465/majozi mpsych 2010.pdf?seque nce $=1 /$.

Mangerud, W. L., Bjerkeset, O., Holmen, T. L., Lydersen, S., \& Indredavik, M. S. (2014). Smoking, alcohol consumption, and drug use among adolescents with psychiatric disorders compared with a population based sample. Journal of Adolescence, 37, 1189-1199.

Morejele, N. K., Kachieng'a, M., Mokoko, E., Nkoko, M. A., Parry, C. D. H., Nkowane, A. M., Moshia, K. M., \& Saxena, S. (2006). Alcohol use and sexual behaviour among risky drinkers and bar and shebeen patrons in Gauteng province, South Africa. Social Science \& Medicine, 62, 217-227.

Neuman, L. W. (1997). Social research methods: Qualitative and quantitative approaches. $3^{\text {rd }}$ edition. London: Allyn and Bacon. 
E. G. Machimana \& P. Nhlanhla - Male Youths' Perceptions, Knowledge and Beliefs of Alcohol...

Newell, M. L. (2007). Male circumcision to cut HIV risk in the general population. The Lancet, 369, 615619.

Nolen-Hoeksema, S. (2008). Abnormal psychology $4^{\text {th }}$ edition. New York: McGraw-Hill Higher Education.

Nong, M. (2011). Personal interview. Soshanguve, Pretoria.

Norris, A. H., Kitali, A. J., \& Worby, E. (2009). Alcohol and transactional sex: How risky is the mix? Social Science \& Medicine, 69, 1167-1177.

Oppong, C., Oppong, M. Y. P. A., \& Odo 'tei, I. K. (2006). Sex and gender in an era of AIDS: Ghana at the turn of the millennium. Accra: Sub-Saharan Publishers.

Parry, C. D. H., Rehm, J. \& Morojele, N. K. (2010). Is there a causal relationship between alcohol and HIV? Implications for policy, practice and future research. African Journal of Drug \& Alcohol Studies, 9(2), 81-91.

Pettifor, A. E., Rees, H. V., Kleinschmidt, I., Steffenson, A. E., MacPhail, C., Hlongwa-Madikizela. L., Vermaak, K., \& Padian, N. S. (2005). Young people's sexual health in South Africa: HIV prevalence and sexual behaviours from a nationally representative household survey. AIDS, 19(14), 1525-1534.

Ratele, K. (2008). Analysing males in Africa: Certain useful elements in considering ruling masculinities. Africa and Asian Studies, 7, 515-536.

Schultz, D. P., \& Schultz, S. E. (2005). The theories of personality. $8^{\text {th }}$ edition. United States: Thomson Wadsworth.

Simbayi, L. C., Mwaba, K., \& Kalichman, S. C. (2006). Perceptions of the combination of HIV/AIDS and alcohol as a risk among STI clinic attenders in South Africa: Implications for HIV prevention. Social behaviour and personality, 34(5), 535-544.

Stueve, A., \& O'Donnell, L. N. (2005). Early alcohol initiation and subsequent sexual and alcohol risk behaviours among urban youths. American Journal of Public Health, 95(5), 887-893.

Trichopoulou, A. (2001). Mediterranean diet: The past and the present. Nutrition Metabolism and Cardiovascular Disease Journal, 11(4), 1-4.

UNAIDS (2008). Report on the global AIDS epidemic. Retrieved 25 April 2019, from http://www.unaids.org/sites/default/files/media asset/jc1510_2008globalreport_en_o.pdf.

Van Dyk, A. (2001). HIV/AIDS care and counselling: A multidisciplinary approach. $2^{\text {nd }}$ edition. Cape Town: Pearson Education South Africa.

Weir, S. S., Pailman, C., Mahlalela, X., Coetzee, N., Meidany, F., \& Boerna, J. T. (2003). From people to places: Focusing AIDS efforts where it matters most. AIDS, 17, 895-903. 